\title{
Os Adolescentes em Situação de Rua e as Instituições de Atendimento: Utilizações e Reconhecimento de Objetivos
}

\author{
Juliana Prates Santana ${ }^{123}$ \\ Thaís Mesquita Doninelli \\ Raquel Valiente Frosi \\ Sílvia Helena Koller \\ Universidade Federal do Rio Grande do Sul
}

\begin{abstract}
Resumo
O presente estudo visou a identificar os significados que os adolescentes em situação de rua atribuem às instituições de atendimento a eles destinadas. Treze adolescentes em situação de rua de 12 a 17 anos, do sexo masculino, encontrados no centro de Porto Alegre foram entrevistados na rua. Os resultados revelaram que as instituições são de extrema importância para estes jovens, sendo responsáveis pelo fornecimento de alimentação, vestimentas, lazer, educação, profissionalização e prestação de cuidados com a higiene e a saúde. As instituições, juntamente com seus funcionários, desempenham um importante papel na sua rede de apoio social e afetivo. Os significados foram compreendidos a partir da utilização e da atribuição de objetivos institucionais, sendo possível, desta forma, melhor entender a relação estabelecida entre os jovens e as instituições de atendimento.

Palavras-chave: Adolescentes em situação de rua; instituições de atendimento; rede de apoio social.
\end{abstract}

The Street Youth and Assistance Institutions: Uses and Recognition of Objectives

\begin{abstract}
The study aims to identify the meanings of institutional agencies for street youth. Thirteen male adolescents, 12 to 17 years old, were interviewed on the streets. The results revealed that the institutions are extremely important to these youngsters, giving food, clothes, leisure, education, job training and health care to those adolescents. The institutions constitute the social support network of the street youth. The institutional meanings were understood by the use and the given attributions related to their goals, showing the established relation between the adolescent and the institution.

Keywords: Street youth; institutional agencies; social support network.
\end{abstract}

O presente estudo objetiva identificar os significados que os adolescentes em situação de rua atribuem às instituições de atendimento. Além disto, visa à verificação do conhecimento que tais adolescentes possuem a respeito das instituições municipais a eles destinadas.

Vários estudos em todo mundo investigaram as principais características de crianças e adolescentes em situação de rua (Aptekar, 1988a, 1989b, 1996; Hecht, 1998; Koller \& Hutz, 1996). Em geral, citam aspectos como: história anterior à inserção na rua; características bio-sócio-demográficas; atividades desenvolvidas pela criança e/ou adolescente na rua; relação com a escola, família e pares; e funcionamento psicológico e neurológico. A história anterior à inserção na rua talvez seja a principal questão a ser enfatizada nas políticas públicas e nas pesquisas sobre crianças que saem de casa para viverem na rua. Desta forma, haveria condições de efetuar um trabalho preventivo, ao invés de simplesmente paliativo. Um conjunto de problemas sociais, políticos e econômicos tem sido relacionado à saída das crianças e dos adolescentes para a rua. Estes jovens em geral vivem, juntamente com suas famílias, em condições de miséria, sendo apontado em alguns estudos que a saída para rua se deve, na maioria das vezes, a questões financeiras. Além disto,

\footnotetext{
${ }^{1}$ Endereço para correspondência: CEP-RUA/UFRGS, Instituto de Psicologia, R. Ramiro Barcelos, 2600, 104, 90035 003, Porto Alegre, RS. Fone: (51) 33165150, Fax: (51)32410074.E-mail:cep_rua@ufrgs.br

${ }^{2}$ As autoras agradecem às instituições participantes do estudo, pelo apoio e disponibilidade.

${ }^{3}$ Apoio institucional para o projeto: CAPES, CNPq, PET/SESu
}

a violência intrafamiliar tem sido amplamente citada (Aneci Rosa, Borba \& Ebrahim, 1992; Aptekar, 1996). Tal violência decorre, muitas vezes, da reprodução de um modelo agressivo, impingido aos próprios cuidadores na infância (Caminha, 1999), mas nem sempre isto é regra, uma vez que há exemplos de superação. É constatado, no entanto, que muitas destas famílias não têm conseguido cumprir de forma eficaz e dedicada as suas funções parentais, devido à alta demanda para a própria sobrevivência (Cecconello, De Antoni \& Koller, 2003). A esta condição enfrentada por crianças, adolescentes e famílias em situação de risco, Alves e colaboradores têm descrito como miséria econômica e afetiva (Alves \& cols., 1999).

Estudos descritivos de adolescentes em situação de rua apontam um maior número de meninos do que meninas nesta situação, variando entre os estudos a magnitude desta diferença (Aptekar, 1996; Martins, 1996a; Raffaelli \& cols., 2000, 2001; Yunes, Arrieche \& Tavares, 1997). Uma das principais justificativas para o maior número de meninos em situação de rua refere-se ao papel social que as meninas desempenham em casa, ao ajudar a cuidar das crianças mais novas e prestarem trabalhos domésticos (Maciel, Brito \& Camino, 1997; Poleto, Koller \& Wagner, 2004; Rizzini, 1995). Portanto as meninas são mantidas em casa e os meninos transitam mais nas ruas, utilizando-as como fonte de trabalho e/ou lazer. Esta saída dos meninos para a rua não é vista como algo tão perigoso, como no caso das meninas, sendo muitas vezes incentivada pelos próprios pais. Os meninos passam a conhecer a rua como uma possibilidade de vida, estando muito mais expostos aos atrativos do viver na rua. Talvez ao conhecer estes atrativos não seja mais possível 
suportar a situação de miserabilidade a que são submetidos. Estas diferentes situações vivenciadas por meninos e meninas devem-se também às concepções culturais de gênero vigentes.

Os adolescentes que estão na rua desempenham, geralmente, atividades como cuidar e lavar carros, vender gêneros alimentícios e outros produtos, engraxar sapatos, mendigar, ou mesmo perambular pelas ruas (Alves, 1998; Martins, 1996a, 1996b; Rosemberg, 1996). Com estas atividades os jovens conseguem dinheiro que é levado, na maioria das vezes, para suas familias (Aptekar, 1996; Maciel \& cols., 1997; Yunes \& cols., 1997). Os adolescentes também utilizam o dinheiro para a compra de alimentos, de substâncias psicoativas, entre outros. É importante reconhecer os ganhos econômicos que a rua oferece, pois as instituições de alguma forma estão concorrendo com este reforço financeiro imediato que, muitas vezes, é superior às bolsas fornecidas pelos programas especializados ou instituições (Maciel \& cols., 1997).

Ainda em relação às atividades que os jovens desempenham nas ruas, deve ser considerada a questão da exploração do trabalho infantil. Muitas vezes, as crianças e os adolescentes ficam na rua desempenhando atividades laborais por exigência dos pais e/ou responsáveis. As constantes campanhas contrárias à exploração do trabalho infanto-juvenil parecem não ser completamente eficazes e isto pode ser justificado pela crença social de que o trabalho é uma atividade dignificante em qualquer circunstância (Campos \& Alverga, 2001). Com isto, parte da população defende que os adolescentes devem ser inseridos o mais brevemente possível no mundo do trabalho, pois assim evitariam a marginalidade, a mendicância, entre outros. Neste sentido, é importante diferenciar a inserção em oficinas profissionalizantes que inserem pedagogicamente os adolescentes no mundo do trabalho e a exploração do trabalho infanto-juvenil, que os expõe a situações de risco e à condições que estão distantes do esperado para um jovem em desenvolvimento.

Os estudos com as crianças e os adolescentes em situação de rua demonstram também que a maioria destes tem ou já teve uma experiência escolar. A principal fonte de rompimento dos vínculos com a escola deve-se à sucessão de fracassos a que a criança e/ou o adolescente são submetidos (Forster \& cols., 1992; Koller, 1994; Vasconcelos, 1996). O alto grau de repetência, as impossibilidades de conciliar a necessidade de trabalhar com a freqüência exigida pela escola e a própria falta de atratividade desta, que muitas vezes apresenta conteúdos distantes da realidade vivida por estes jovens, também são razões que promovem o abandono da instituição escolar. Cerqueira-Santos (2004) aponta para o fato de que as crianças informam que a escola não é um lugar de brincar. Parece bastante surpreendente que um lugar onde há tantas crianças juntas, seja identificado por eles como tal. Certamente isto se dá, como aponta Cerqueira-Santos, pela dificuldade da escola em acolher a infância em situação de risco que eles vivem. Contudo, é importante ressaltar a importância que a escola desempenha na vida e no imaginário destas crianças, que a considera como uma das formas possíveis de mudança de status social (Koller, 2001; Kuschick \& cols., 1996).
A relação dos meninos e meninas em situação de rua com os seus pares também tem sido discutida em muitos estudos (Alves, 1998; Forster \& cols., 1992; Menezes \& Brasil, 1998). Cerqueira-Santos (2004) verificou, também, que estes jovens, em geral, vivem em pequenos grupos que obedecem a uma hierarquia e que possuem regras específicas e um vocabulário particular. As instituições e/ou pesquisas com esta população devem considerar este importante aspecto relativo ao viver na rua. O grupo da rua exerce uma forte influência no jovem, fator a ser considerado nos programas de inserção das crianças e dos adolescentes em instituições. Além disto, a compreensão das particularidades do vocabulário cotidiano é fundamental para que jovens e instituições possam estabelecer um contato inicial mais eficaz no estabelecimento do vínculo futuro.

Por fim, a participação em instituições ou programas é considerada como uma importante característica compartilhada pelas crianças e pelos adolescentes em situação de rua. Tratamse de instituições e programas governamentais, nãogovernamentais ou religiosos que estão à disposição destes jovens prestando os mais diversos serviços, tais como: fornecimento de alimentação, educação, lazer e prestação de cuidados com a higiene e a saúde. Bandeira, Koller, Hutz e Forster (1994) apontaram, em seu estudo com crianças e adolescentes em situação de rua, que quase cem por cento deles referiam-se às instituições de recreação e/ou oficinas profissionalizantes como contextos importantes no seu dia-a-dia. Estes resultados corroboram os dados obtidos por Forster e colaboradores (1992), que reafirmam a capacidade de envolvimento dos jovens em situação de rua com pessoas e instituições. Este aspecto também foi enfatizado por Brito (1999), que salientou o importante papel desempenhado pelas instituições de atendimento, assim como seus funcionários, jna rede de apoio social e afetivo das crianças e adolescentes em situação de rua.

Em função da importância das instituições de atendimento na vida dos jovens em situação de rua, realizou-se o presente estudo que objetivou, então, identificar os significados que os adolescentes em situação de rua atribuem a estes locais. Além disto, visou a verificar o conhecimento que estes jovens possuem acerca das instituições de atendimento a eles destinadas. Para tal, a seguir serão apresentados os participantes, instrumentos e procedimentos, assim como os resultados e discussão deste estudo. Os resultados serão ilustrados com as falas dos adolescentes, sendo necessário apontar que foram realizadas algumas adaptações gramaticais para facilitar o entendimento do leitor acerca dos conteúdos das mesmas.

\section{Método}

\section{Participantes}

Participaram deste estudo 13 adolescentes em situação de rua, com idades entre 12 e 17 anos, do sexo masculino, encontrados nas ruas do centro de Porto Alegre. Estes adolescentes foram identificados por características exteriores, tais como: aspecto de abandono e de falta de higiene, vestimentas simples que estivessem 
sujas e/ou rasgadas, prática de atividades anteriormente descritas como sendo características desta população e ausência de um adulto identificado como responsável. estes critérios foram sugeridos por Alves (1998) e Neiva-Silva e Koller (2002). Alguns adolescentes já haviam tido alguma experiência com as instituições existentes na cidade, e que têm como população alvo aqueles que vivem na rua. São principalmente escola, serviço de saúde, abrigo, instituição para cumprimento de medida socio-educativa.

\section{Instrumento}

Foi utilizada uma entrevista semi-estruturada com os objetivos de: a) coletar dados bio-sócio-demográficos dos participantes, tais como: idade, sexo, experiência escolar e com o trabalho, local de moradia e atividade de lazer; e, b) identificar os significados que o adolescente em situação de rua atribui às instituições de atendimento. As entrevistadoras iniciavam o contato solicitando ao participante para descrever um dia de sua vida, onde se alimenta, dorme, toma banho, se diverte, além de que lugar/pessoa procura quando se machuca, fica doente ou sente medo. Em seguida, era perguntado se o adolescente já foi em algum lugar para crianças e/ou adolescentes, tais como escolas, abrigos, casas de passagem, postos de saúde e caso a resposta fosse afirmativa, eram questionados sobre como chamavam estas instituições e para que elas serviam. Além disto os participantes eram solicitados a descrever uma instituição a qual gostariam de frequentar e como ela deveria ser. Caso nenhuma instituição fosse citada, as entrevistadoras perguntavam diretamente se os participantes conheciam as existentes na cidade e por que não as freqüentavam.

\section{Procedimentos}

A primeira etapa da coleta de dados consistiu na identificação do adolescente em situação de rua a partir dos critérios anteriormente descritos. Após identificado, o adolescente foi abordado pelas entrevistadoras que se apresentaram como sendo da universidade e solicitavam sua anuência para participar da pesquisa. Os objetivos do estudo foram explicados para o participante da forma mais simples possível, utilizando-se um vocabulário adequado para eles. Aceitas a participação na pesquisa e a utilização do gravador, iniciava-se a coleta de dados em um local escolhido pelo adolescente.

A próxima etapa consistia na aplicação da entrevista semiestruturada, que era aplicada em um único encontro, com duração média de 20 minutos. As entrevistas foram realizadas preferencialmente com cada adolescente separadamente, para que as respostas de um não influenciassem as respostas dos outros adolescentes presentes. Situações adversas para coleta de dados (interrupções de outros adolescentes, eventos dispersores, desinteresse do participante) são comuns nas pesquisas com crianças e adolescentes em situação de rua, evidenciando-se a necessidade de capacitação dos entrevistadores. A presença de duas pesquisadoras durante as entrevistas foi de grande importância nestas situações em que havia mais de um adolescente no local, uma vez que enquanto uma realizava a entrevista, a outra mantinha entretidos os demais adolescentes que estavam por perto.

\section{Resultados e Discussão}

As entrevistas foram transcritas, sendo os dados submetidos à Análise de Conteúdo (Bardin, 1979). A Tabela 1 apresenta a caracterização dos participantes por idade, vinculação a uma instituição de ensino, realização de trabalho, obtenção de dinheiro na rua, contato com a familia e a última ida do adolescente à sua casa.

Um primeiro aspecto a ser discutido refere-se ao fato de todos os participantes do presente estudo serem do sexo masculino. Esta não foi uma condição inicial para determinar a participação dos adolescentes, mas um resultado da coleta de dados propriamente dita. Esta predominância de jovens do sexo masculino em situação de rua é constantemente mencionada pela literatura, sendo corroborada pelos dados deste estudo (Aptekar, 1996; Martins, 1996a; Raffaelli \& cols., 2000, 2001; Yunes \& cols., 1997). Os jovens do sexo masculino que estavam na rua, como nos estudos citados, informavam estar em busca de ocupação, dinheiro, precisando, em sua maioria, conseguir auxilio para levarem para suas famílias ou para comprarem drogas na rua.

Em relação à relação com a instituição escola, onze adolescentes afirmam ir à escola, sendo que sete citam a instituição municipal especificamente destinada a esta população, dois indicaram uma escola formal vinculada a esta, um afirmou estar vinculado às duas instituições e outro adolescente mencionou uma escola desconhecida para o grupo de entrevistadoras. Dois participantes não estavam vinculados a nenhuma instituição de ensino, sendo que apenas um participante não possuia experiência escolar. Estes dados corroboram a literatura que aponta o elevado número de crianças e adolescentes em situação de rua que têm ou tiveram experiência escolar (Forster \& cols., 1992; Koller, 1994; Kuschick \& cols., 1996; Vasconcelos, 1996). Fica evidente também que, pelo fato dos adolescentes estarem na rua em horários variados do dia, mesmo possuindo matrícula na escola, não a freqüentam diariamente. É interessante questionar este elevado número de adolescentes que afirma freqüentar a escola, pois o que pôde ser constatado ao longo da entrevista é que esta ida à escola é extremamente esporádica ou não ocorre: Estudo mais ou menos... Eu não vou faz, 2 anos... eu acho (G, 14 anos). Outro exemplo é a afirmação: Vou [à escola], mas tô parado (C, 12 anos).

Há duas razões para a contradição encontrada nos resultados sobre a relação estabelecida entre o adolescente e a escola. Uma delas refere-se às respostas socialmente aceitas que os adolescentes costumam fornecer, à medida que sabem que a vinculação a alguma instituição de ensino é uma das maiores exigências sociais feita para esta faixa etária. A outra razão diz respeito ao fato de que a maioria dos adolescentes entrevistados está vinculada a uma escola aberta, cujas características possibilitam este tipo de resposta, uma vez que são dedicadas especialmente a esta população e toleram a condição itinerante e a falta de freqüência. A ida para esta escola aberta, destinada especificamente à 
população em situação de rua, é livre e espontânea, permanecendo os adolescentes matriculados na instituição até que sejam transferidos para outro local. A matrícula consta, inclusive, nos registros da Secretaria Municipal de Educação, o que legitima a condição de matriculados destes adolescentes e acarreta uma série de questões a serem discutidas: Pode-se considerar que este adolescente realmente está vinculado a uma escola? Será que o fato de estar realmente matriculado em uma instituição escolar não leva o adolescente a se iludir no sentido de estar inserido socialmente? Além disso, deve ainda ser considerado este dado enquanto contribuinte para as pesquisas divulgadas pelos órgãos governamentais, que afirmam que grande parte dos jovens brasileiros em idade escolar está matriculada em instituições de ensino. Ao mesmo tempo, não se pode desconsiderar que a referência à escola é um aspecto salutar para o desenvolvimento destes jovens, pois demonstram o reconhecimento da importância desta instituição por parte deles. No entanto, fica evidente que suas experiências com a escola, vínculos reais e freqüência efetiva são aspectos nebulosos, que variam deste a presença diária até a matrícula como uma condição exigida e mencionada, sem implicação com a freqüência e ao atendimento das exigências à instituição escola.

Em relação ao trabalho, é importante ressaltar que as atividades consideradas como tal foram aquelas que os próprios adolescentes assim definiram. Por isto houve vezes em que o mesmo tipo de atividade foi considerado como trabalho para um adolescente e não para outro. Relativo a esta experiência, sete adolescentes afirmaram não desempenhar atividade nenhuma. Seis adolescentes informaram trabalhar, sendo que dois deles mencionaram cursos profissionalizantes que freqüentavam, dois realizavam trabalhos esporádicos, um era engraxate e acerca do outro não se possui esta informação.

Chama atenção o fato dos adolescentes afirmarem que os cursos profissionalizantes oferecidos pelas instituições são atividades de trabalho, pois representa uma forma substituta para a obtenção de recursos financeiros. Um dos adolescentes afirmou, inclusive, que não roubava mais em função do dinheiro que recebia como auxílio para participar do curso: Antes que en tava no curso eu roubava, né?... Agora en ganbo cento e cinqüenta reais já, que épra eu não roubar já. Ganhando 150 não precisa da gente tá roubando ( $K, 16$ anos). Sabe-se que o valor das bolsas-auxilio é inferior ao valor que pode ser obtido a partir da realização de outras atividades. Contudo, participar destes cursos pode significar a saída do adolescente da ilegalidade, facilitando desta forma o processo de inclusão social objetivado pela maioria das instituições que atende esta população. Conforme indicado por Bandeira e colaboradores (1994), o vínculo com uma instituição que oferece um programa de oficina escola ou de profissionalização pode ser a ponte para a reinserção destes jovens na escola, uma vez que representam uma atividade de interesse, que auxilia na sobrevivência e que em si mesmos são programas de prevenção ao uso de drogas e ao envolvimento em comportamentos de risco.

Dez adolescentes afirmam obter dinheiro na rua, afora os ganhos financeiros provenientes do trabalho. Entre estes, oito obtêm dinheiro através da mendicância, um a partir de "biscates" realizados na rua e não foram identificados os meios utilizados pelo outro participante para obtenção de dinheiro. Muito estudos têm apontado para a necessidade que estes jovens têm de auxiliar em suas casa e algumas vezes de serem responsáveis pela subsistência de suas famílias (Aptekar, 1996; Maciel \& cols., 1997; Yunes \& cols., 1997). Em um estudo com as famílias destes jovens este aspecto foi muito evidente, mas também foi salientado o progressivo afastamento deles de suas residências e inserção na vida da rua (Carpena \& Koller, 1999).

O ganho financeiro obtido nas ruas é uma das questões mais difíceis de ser discutida e avaliada quando se estuda a realidade dos adolescentes em situação de rua. Afinal esta é uma das razões que motivam os adolescentes a preferirem a rua a outros ambientes. A atual situação econômica do país faz com que um número expressivo de famílias sobreviva abaixo da linha de miséria, tornando atraente a possibilidade de conseguir diariamente ganhos significativos através da mendicância e outras atividades, algumas vezes ilícitas. Estes valores são utilizados para aquisição de alimentos, vestimentas, drogas e financiamento de atividades lúdicas, tais como, fliperamas e vídeo games. Este é um importante aspecto, pois demonstra que a instituição não apenas concorre diretamente com o ganho fácil na rua, mas também com os benefícios obtidos a partir dele. Neste impasse, os adolescentes passam a optar entre o ambiente institucional e o da rua, uma vez que suas necessidades básicas podem ser supridas sem a intervenção dos serviços de atendimento.

Ainda em relação à obtenção de ganhos financeiros na rua, é necessário ressaltar a importância preventiva das campanhas que solicitam à população o não fornecimento de esmolas, sejam estas em forma de dinheiro ou outros benefícios. A caridade e o assistencialismo funcionam, neste caso, como um grande atrativo para a rua, criando um círculo vicioso extremamente perverso e legitimando a condição de pedintes e necessitados. A criança, o adolescente e suas famillias vão, muitas vezes, para a rua visando à sobrevivência, que é garantida, então, a partir destas esmolas. Como a sociedade dá, algumas vezes para aliviar suas culpas, outras para se "livrarem" do incômodo que se aproxima deles, em forma de criança ou adolescente, esta condição passa a ser assumida e utilizada, impedindo a busca de outras estratégias de superação da condição de risco.

A manutenção do contato com a familia foi identificada em nove adolescentes, embora haja grandes variações na freqüência deste contato. Quatro participantes afirmaram ter ido à sua casa há menos de uma semana, um há um mês, um há dois meses da realização da entrevista e dois não determinaram a data da última ida à casa. Esta imprecisão e variabilidade deve-se à nãorecordação por parte do adolescente desta data, ao longo período transcorrido desde o fato ou por associarem a última ida à casa a um evento qualquer ocorrido no passado, que não conseguiam precisar. Três adolescentes afirmam não manter contato com a família. Tais informações corroboram, de uma maneira geral, a literatura e demonstram a existência de vínculos, 
Tabela 1

Dados Bio-Sócio-Demográficos dos Adolescentes em Situacão de Rua de Porto Alegre

\begin{tabular}{ccccccl}
\hline Identificação & Idade & Estuda & Trabalha & Obtenção de dinheiro na rua & Contato com família & Última ida para casa \\
\hline A & 12 & S & N & S & S & indeterminado \\
B & 12 & S & N & S & S & há um dia \\
C & 12 & S & N & S & S & SI ${ }^{1}$ \\
D & 13 & S & S & S & N & indeterminado \\
E & 13 & S & S & S & S & há uma semana \\
F & 14 & S & N & S & SI & há um dia \\
G & 14 & S & S & S & N & SI \\
H & 14 & N & N & S & S & há um mês \\
I & 14 & S & N & SI & N & SI \\
J & 16 & S & S & SI & S & há um dia \\
K & 16 & S & S & S & S & há dois meses \\
L & 16 & N & N & S & S & indeterminado \\
M & 17 & S & S & SI &
\end{tabular}

${ }^{1}$ A expressão Sem Informação (SI) foi utilizada nos casos em que a questão não foi feita ao participante ou naqueles em que a criança e/ou o adolescente dispersou-se no momento da coleta não fornecendo o dado solicitado.

na maioria dos casos entre os adolescentes em situação de rua e seus familiares (Alves, 1998, 2002; Santana \& cols., 2000). A idéia de uma criança ou adolescente totalmente abandonado, sem nenhum contato com familiares, mais uma vez é constatada como falsa. Obviamente, as relações que são estabelecidas entre estes meninos e suas famílias merecem uma atenção especial. Em geral, o contato é reduzido e, muitas vezes, as razões que motivaram a ida do adolescente para a rua estão relacionadas à ocorrência de problemas familiares, com episódios de violência doméstica, privação de recursos financeiros, perda ou ausência de um dos genitores, etc. Além disto, mesmo que não haja mais contato com a família, os adolescentes reconhecem a importância da família em suas vidas, mesmo que, às vezes, de forma idealizada: Eu nunca vou duvidar de um irmão que... irmão é irmão, né? Ninguém duvida do irmão de ninguém (D, 13 anos). Para alguns adolescentes a familia desempenha um papel protetivo, sendo considerado como seu integrante todo aquele que assume papéis similares, mesmo que sem parentesco ou consangüinidade: E asprofessoras, aspessoas que ajudam nós, né? É da família $(\mathrm{K}, 16$ anos). Este tipo de resposta permite compreender o quanto as instituições e seus integrantes podem ser significativos no desenvolvimento destes adolescentes.

Finalizada a análise dos dados bio-sócio-demográficos, serão apresentados os resultados referentes à segunda parte da entrevista semi-estruturada. Cabe ressaltar que todos os adolescentes participantes deste estudo já freqüentaram ou freqüentam instituições de atendimento, tendo-as referido durante a entrevista. Este dado concorda com os obtidos por Bandeira e colaboradores (1994), que salientaram tal importância e o conhecimento e experimentação realizada por estes jovens nas variadas instituições do contexto no qual viviam.

Os significados propriamente dito que os adolescentes em situação de rua atribuem às instituições de atendimento a eles destinadas foram analisados a partir das utilizações que estes meninos fazem das instituições e a partir dos objetivos que estes adolescentes atribuem a estas. Foram definidos os significados, justamente, pela combinação destas duas dimensões, não sendo possível compreendê-los a partir da análise isolada de uma delas.

As utilizações que os adolescentes fazem das instituições foram identificadas ao longo de toda a entrevista e se referem ao uso concreto que eles fazem dos recursos disponíveis nos serviços de atendimento, especialmente quando perguntados onde dormem, se alimentam, buscam auxílio e lazer. A atribuição de objetivos institucionais foi identificada, por sua vez, a partir da questão: Você acha que estas instituições servem para quê? As respostas a esta questão revelam a compreensão que os adolescentes fazem dos recursos disponíveis e dos objetivos das instituições freqüentadas. É importante ressaltar que as duas dimensões utilização e objetivos - foram criadas a partir da análise das entrevistas, sendo esta diferenciação indispensável para a compreensão dos significados atribuídos pelos adolescentes às instituições de atendimento. Cada uma destas dimensões será apresentada e discutida separadamente.

Em relação às utilizações que os adolescentes fazem das instituições foram identificadas 13 categorias. Estas foram extraídas a partir da Análise de Conteúdo (Bardin, 1979) das próprias entrevistas, sendo apresentadas juntamente com a freqüência de aparecimento na Tabela 2.

Doze participantes referem-se à alimentação obtida nas instituições, demonstrando a importância desta na sua relação com este local. Isto pode ser constatado pela ênfase dada pelos adolescentes às refeições fornecidas por estes serviços, sendo que em alguns momentos a rotina da instituição é descrita exclusivamente em função deste aspecto: depois nós jantamos, depois às 11 horas tem lanche, e de manhã bem cedo, seis horas, tem café da manhã (G, 14 anos). Além disto, a alimentação é algumas vezes apontada como o principal atrativo institucional: A coisa que eu mais gosto lá é o rango (F, 14 anos). A utilização do espaço institucional para tal não é por si só algo problemático. As dificuldades iniciam-se quando o adolescente utiliza o espaço institucional apenas com o objetivo de alimentar-se: Depois como... almoģo. Depois lancho, o lanche das três e depois vou embora (I, 14 anos). 
Tabela 2

Freqüencia das Categorias de Utilização Institucional Obtidas em Entrevista com Adolescentes em Situação de Rua de Porto Alegre

\begin{tabular}{lc}
\hline Categoria & Freqüência $(n=13)$ \\
\hline Alimentação & 12 \\
Dormir & 12 \\
Higiene pessoal & 12 \\
Atividades de entretenimento & 12 \\
Cuidados com a saúde & 11 \\
Papel pedagógico & 5 \\
Encaminhamento & 5 \\
Proteção & 4 \\
Cumprimento de medidas sócio-educativas & 4 \\
Obtenção de vestimentas & 3 \\
Papel profissionalizante & 3 \\
Tratamento do abuso de substâncias psicoativas & 2 \\
Local para não se estar na rua & 1 \\
\hline
\end{tabular}

A utilização da instituição como espaço para dormir é citada também por 12 adolescentes: lá no abrigo é um lugar onde dá pra dormir (A, 12 anos). Os participantes não se referem apenas ao período noturno, referindo-se à instituição também como local adequado para descansar durante o dia: Se quiser dormir lá, descansar lá, tem uma sala (B, 12 anos). As condições oferecidas pelas instituições para que os adolescentes durmam são consideradas, algumas vezes, como o aspecto mais interessante, mais legal do serviço: ( $\mathrm{O}$ que tem de mais legal lá?) Tem cama pra dormir (L, 16 anos).

Doze adolescentes informam usar a instituição para a realização da higiene pessoal: primeiro a gente toma um banho $(\mathrm{H}, 14$ anos). O banho é, muitas vezes, encarado pelos adolescentes como obrigação, sendo que as próprias instituições utilizam mecanismos que garantem o cumprimento desta norma: Depois do banho pega a ficbinha... Ai entrega para a cozinheira. A cozinheira dá a comida. Se não tiver ela não dá. Porque tem que tomar banho (D, 13 anos). Por outro lado, a realização da higiene pessoal é uma das atividades mais difíceis de serem desempenhadas pelos adolescentes em situação de rua fora do espaço institucional, tornando-se um importante atrativo destes espaços.

A utilização das instituições para a realização de atividades de entretenimento é citada por 12 adolescentes: $A$ gente joga videogame, joga futebol, jogo snooker, fla-flu (A, 12 anos). As atividades de entretenimento são citadas como sendo os maiores atrativos da instituição para diversos adolescentes. O espaço institucional é citado por alguns adolescentes como o lugar preferido para a diversão. Isto demonstra que as instituições são ambientes avaliados positivamente pelos adolescentes, propiciando um espaço de lazer e entretenimento. A interação com os funcionários também é considerada como fonte de diversão pelos adolescentes: Eu ficava conversando com os monitores. Brincando com eles lá (K, 16 anos). Quando questionado sobre o que mais gostava de fazer na instituição um participante afirma: Desenhar. Brincar com os guris, com os guardinha (D, 13 anos).

Onze meninos referem-se a uma instituição específica como local adequado para a realização de cuidados com a saúde: É... a gente tá com um machucado, elas dão um remédio. A gente tá doente, eles dão comprimido, um remédio, pomada (J, 16 anos). Os participantes reconhecem que podem ter acesso a instituições de saúde via outros serviços da rede de atendimento a esta população. Os funcionários das instituições também são citados como pessoas de referência caso o adolescente esteja necessitando de cuidados com a saúde, ressaltando mais uma vez o importante papel que tais pessoas desempenham na vida destes meninos: A tia da enfermaria é tri, ela cuida o cara (E, 13 anos).

$\mathrm{O}$ uso da instituição para a realização de atividades pedagógicas é citado por cinco adolescentes: Estudamos, fazemos as tarefas que têm que fazer lá, do colégio (M, 17 anos). Em alguns casos, a atividade pedagógica é considerada de forma muito positiva pelo adolescente, sendo que isto pode ser exemplificado pela resposta dada por um participante ao ser questionado sobre o que havia de bom na instituição: Tudo! Eles dão colégio (G, 14 anos).

Cinco adolescentes referem-se aos encaminhamentos realizados pelas instituições: É encaminhado, se não tiver remédio certo é encaminhado pra outro lugar, eles encaminham, fazem, fazem tudo direitinho (M, 17 anos). Nesta fala, o encaminhamento representa o trabalho em rede que é desenvolvido pelas instituições, havendo uma complementaridade nos trabalhos desenvolvidos em cada um destes locais. No entanto, é importante que o encaminhamento não signifique delegar responsabilidades de um local para o outro, pois desta forma os adolescentes que aparentemente podem contar com vários serviços, passam a não serem beneficiados por nenhum deles. Os encaminhamentos também representam a reinserção dos adolescentes em escolas das comunidades de origem ou em cursos profissionalizantes realizados por outras instituições.

Quatro adolescentes salientam claramente o papel de proteção que a instituição desempenha. A instituição é citada como local de referência quando os adolescentes sentem medo de algo: Dai en fiquei com medo e pulei de volta da rua... [para a instituição]. (D, 13 anos). Ao serem questionados a quem pedem ajuda nestes momentos de medo nomeiam também aos funcionários das instituições: ... as tias do abrigo (K, 16 anos).

Quatro adolescentes já estiveram em instituições para o cumprimento de medidas sócio-educativas. Esta é uma das funções também considerada pelos participantes a respeito das instituições: E se agredir chama a polkicia e leva pro DECA_[Delegacia de Polícia Divisão de Crianças e Adolescentes]... lá que leva pra FEBEM [Fundação Estadual do Bem-Estar do Menor], se tiver alguma coisa grave (D, 13 anos). A presença desta categoria demonstra que os usos que o adolescente faz da instituição não estão relacionados, necessariamente, a uma escolha individual, e nem mesmo que eles entendam ou reconheçam que tais instituições cumprem seu papel socioeducativo. A menção a esta função ocorre mais em função do conhecimento que os adolescentes têm do Estatuto da Criança e do Adolescente e da terminiologia que é utilizada pelos funcionários das diversas instituições que atendem, ao mencionarem a antiga Febem (atual Fase).

Três adolescentes utilizam os serviços das instituições também para a obtenção de vestimentas: É por causa que eles são legal, dão tudo, dão roupa. (H, 14 anos). Mesmo utilizando as instituições com este objetivo, os participantes criticam o aspecto 
das vestimentas obtidas nas instituições e afirmam que se pudessem vestiriam apenas roupas novas: mudava todas roupa, en botava tudo roupa nova, tênis novo, meia nova, tudo novo (G, 14 anos).

Três adolescentes indicam o papel profissionalizante desempenhado pelas instituições, citando os cursos a que estão ligados: Eu faco curso de tarde. Curso de padaria (J, 16 anos). Parecem reconhecer que estes locais podem capacitá-los para a entrada no mercado de trabalho. Tal entrada é uma das possibilidades de reinserção social que a instituição pode oferecer. Como já mencionado, os adolescentes valorizam de tal forma esta experiência a ponto de considerá-la como um trabalho em si e não como uma etapa no processo de formação profissional: Eu trabalho... bem dizendo não é um trabalho. É um curso (K, 16 anos).

Dois participantes usam as instituições para o tratamento do abuso de substâncias psicoativas: Se eu tiver muito mal da loló... me dão soro, depois eu tenho que fazer um tratamento lá (D, 13 anos). O baixo número de referências é contrastante com o elevado número de adolescentes em situação de rua que fazem uso de substâncias psicoativas. Cabe questionar se isto ocorre em decorrência de um desinteresse dos adolescentes em buscar tratamento ou se por uma dificuldade das instituições em oferecer um serviço efetivo com esta finalidade. Talvez indique ainda o apelo para o uso de drogas que está disponível na rua.

Um adolescente utiliza a instituição como espaço alternativo ao estar na rua: Lá no abrigo é um lugar onde dá pra dormir, pra não viver na rua (A, 12 anos). É relevante pontuar que a simples leitura desta resposta poderia ser interpretada como pertencente à dimensão de atribuição de objetivo institucional, que será descrita posteriormente. Contudo, conclui-se a partir da leitura da entrevista que se trata de uma utilização feita pelo adolescente do espaço institucional. Uma possibilidade para esta aparente semelhança na resposta é o significado congruente que o adolescente possui da instituição, uma vez que as dimensões utilização e reconhecimento de objetivos são semelhantes e/ou complementares.

Apresentadas as respostas referentes à dimensão utilização, serão apresentados os resultados da segunda dimensão do conceito de significado que consiste na atribuicão de objetivos institucionais pelos adolescentes. Esta dimensão foi identificada exclusivamente pela análise da seguinte questão da entrevista: Você acha que estas instituicōes (escola, abrigo, casa de passagem, posto de saúde) servem para quê?? As respostas foram agrupadas em sete categorias, a partir da Análise de Conteúdo (Bardin, 1979) das entrevistas, sendo suas freqüências apresentadas na Tabela 3.

Cinco participantes afirmaram que o papel da instituição é tirar a criança e/ou o adolescente da rua. Em um primeiro momento parece se tratar de um reconhecimento do principal objetivo institucional, que seria a reinserção social deste jovem. Contudo, na fala dos adolescentes é possível identificar que este tirar da rua refere-se apenas à saída temporária deste espaço, não estando incluída a noção de reinserção ou saída permanente. Um participante aponta que a justificativa da instituição para não os deixar na rua é a preservação da ordem social: Pra não ficar na rua, incomodando os outros, não tocar pedra em ninguém (E, 13 anos).
Tabela 3

Frequiencia das Categorias de Atribuição de Objetivos Institucionais Atribuidos por adolescentes em Situaşão de Rua de Porto Alegre

\begin{tabular}{lc}
\hline Categoria & Freqüência $(n=13)$ \\
\hline Tirar da rua & 5 \\
Realização das atividades cotidianas & 4 \\
Proteção & 3 \\
Papel pedagógico & 3 \\
Tirar das drogas & 2 \\
Propiciar encaminhamentos & 1 \\
Não sei & 1 \\
\hline
\end{tabular}

Quatro adolescentes definiram o objetivo das instituições como sendo a realização de atividades cotidianas, como expresso por uma seqüência de utilidades institucionais: Pra dormir, pra comer, pra dar roupa, pra tomar banho, trocar de tênis, trocar de roupa, tomar banho, lavar a cabeca, lavar os ouvido... escovar os dentes (G, 14 anos). Foram incluídas nesta categoria as respostas que se referiam à alimentação, higiene pessoal, atividades de entretenimento, cuidados com a saúde e local para dormir. Percebe-se que esta categoria engloba, então, os cinco primeiros aspectos citados como sendo os usos que os adolescentes fazem do espaço institucional.

Três adolescentes afirmam que o objetivo da instituição é protegêlos dos diversos perigos existentes, principalmente os característicos do ambiente da rua. Foram englobadas nesta categoria as respostas que se referiam a "cuidar" e a "acolher": pra acolher nós (C, 12 anos) e .pra cuidar daspessoas que moram na rua (H, 14 anos). É necessário ressaltar que dentro do serviço de atendimento às crianças e adolescentes em situação de rua a palavra acolher é constantemente utilizada com o sentido de possibilitar o acesso do jovem ao local. Desta forma, os adolescentes podem também utilizar a palavra acolher com este sentido, mas pela leitura geral das entrevistas inferiu-se que estas respostas possuem o sentido de proteção. Esta é uma questão a ser posteriormente aprofundada de forma a entender de uma melhor maneira qual é exatamente o significado que estes jovens atribuem às instituições.

Três adolescentes afirmam que o objetivo institucional é promover o ensino: pra ensinar nós (I, 14 anos). É interessante pontuar a contradição existente entre o fato de onze adolescentes possuírem vinculação com a escola e o pequeno número de jovens que reconhecem o ensino como um objetivo institucional. Isto demonstra que, em muitos casos, os adolescentes apesar de freqüentarem a instituição não reconhecem seus objetivos. Este é um dado preocupante, pois aponta para um uso da instituição que não está vinculado com o objetivo da mesma, o que pode dificultar a efetividade destes locais.

Dois participantes afirmam que o objetivo institucional é tirar das drogas: Láé mais pra tirá a gurizada das drogas (M, 17 anos). Estes adolescentes reconhecem que este é um difícil objetivo a ser alcançado e que depende muito mais da força de vontade individual do que do trabalho da própria instituição: $O$ cara tem que querer. Ele mesmo tem que querer se ajudar. Não adianta o cara ir pra um bagulho e fazer bobagem e sair (K, 16 anos). Este é um ponto 
extremamente delicado, pois como constatado por Santana (2003) não há, para esta população, um serviço efetivo de tratamento para o abuso de substâncias psicoativas na cidade.

Um participante refere-se à instituição como responsável por propiciar encaminhamentos: ... e encaminharpra outros lugar(M, 17 anos). Esta fala remete a duas importantes questões, sendo que a primeira é a constatação de que os adolescentes reconhecem a organização em rede das instituições. A segunda questão refere-se a uma prática comum dos serviços públicos em geral, que é o encaminhamento. Esta parece ser uma palavra mágica a partir da qual tudo se resolve. A criança e/ou o adolescente é atendido por diversos serviços cuja ação principal é realizar encaminhamentos.

Um adolescente afirma não saber o objetivo institucional: Não sei... Só vou lá pra dormir (F, 14 anos). Este é um dado a ser considerado com bastante cuidado, uma vez que este adolescente em vários momentos da sua entrevista se referiu a diversas instituições. Obviamente, pode-se tratar apenas da falta de interesse em responder à questão, mas também pode revelar que o objetivo institucional não fica tão claro quanto deveria. Talvez a própria instituição permita, sem se dar conta disto, que o adolescente utilize os seus serviços imediatos, sem necessariamente se engajar em seu projeto de trabalho.

Em relação a outros aspectos referentes às instituições que foram abordados pela entrevista, pôde-se constatar a freqüência dos adolescentes aos diversos tipos de instituições. No entanto, esta difere bastante entre os participantes, variando também em função da instituição referida. Em geral, trata-se de uma freqüência bastante irregular, alternada pela ida dos adolescentes às ruas ou às suas casas. Além disto, os adolescentes afirmam freqüentar as instituições, mesmo tendo transcorrido um longo período de tempo desde a sua última ida ao local. Em alguns casos, os adolescentes não sabem precisar a última vez que estiveram nos mesmos. Outra interessante questão diz respeito às afirmações feitas pelos adolescentes acerca da freqüência a instituições e/ou programas aos quais ainda não estão vinculados, mas que aparentemente fazem parte das possibilidades de encaminhamento oferecidas pela rede de atendimento. Isto demonstra que estes locais de atendimento contribuem de maneira significativa na elaboração de projetos de vida dos adolescentes, mesmo que a curto prazo.

Além de freqüentarem as instituições, os adolescentes possuem um conhecimento acerca do seu funcionamento. Este fato pode ser constatado a partir das descrições detalhadas que fazem das rotinas institucionais. Muitas vezes, o adolescente espontaneamente descreve o cotidiano da instituição:

chega as sete hora nós ficamos lá na frente esperando para entrar, na fila, aí depois nós pegamos, entramos, vamos, vamos lá tomamos um banho, depois jantamos, depois vamos olhar filme, depois do filme, depois que termina o filme nós vamos, nós lanchamos, depois do lanche nós vamos dormir, depois, depois que nós, depois que nós dormi chega de manhã nós vamos tomar café, depois quem quer ir pro colégio eles levam pro colégio de Kombi (E, 13 anos).

Uma justificativa para tal descrição pode ser a importância que os adolescentes dão a esta rotina repetida diariamente. Isto difere enormemente das vivências que estes jovens têm nas ruas, podendo representar uma possibilidade de constância, muitas vezes, positivamente avaliada pelos meninos: Funciona legal, sempre a mesma coisa (M, 17 anos).

Um importante aspecto mencionado pelos adolescentes diz respeito à não-freqüência às instituições. Ao contrário do que se poderia supor, esta não pode ser justificada simplesmente pelos aspectos que desagradam os adolescentes nestes locais. Muitos deles asseguram, inclusive, não haver nada que não gostem na instituição, estando a sua não-ida relacionada a questões externas ao local. Os adolescentes apontaram, principalmente, o uso das substâncias psicoativas como motivo para não estarem nas instituições.

A execução deste estudo confirmou o quanto as instituições de atendimento estão presentes na vida dos adolescentes em situação de rua. Estes demonstram amplo conhecimento acerca da dinâmica e funcionamento institucional. As instituições, assim como os seus funcionários, desempenham um importante papel na vida destes meninos e contribuem para o seu desenvolvimento. Isto ocorre porque estes locais garantem as condições mínimas para a sobrevivência destes jovens e compõe de forma significativa a rede social e afetiva destes adolescentes, corroborando os dados obtidos por Brito (1999).

Por fim, é preciso pontuar que independente dos significados que os adolescentes em situação de rua atribuem às instituições de atendimento, que efetivamente existem e estão à disposição da população jovem em situação de rua, deve haver uma prática nestes locais de expor seus objetivos. Uma possibilidade é a realização de grupos focais com os adolescentes visando a apresentar e discutir a missão e os objetivos institucionais. Os jovens podem não usar as instituições com os mesmos objetivos propostos pelos locais, mas devem ser capazes de identificá-los. Afinal o reconhecimento de objetivos é um primeiro passo para que o jovem possa utilizar a instituição como uma forma de sair da rua. É evidente, no entanto, que as características, objetivos e dinâmicas das instituições, bem como as diferenças de atendimento, utilidade e objetivos são claramente capturados e expressos pelos adolescentes.

\section{Referências}

Alves, P. B. (1998). O brinquedo e as atividades cotidianas de crianças em situação de rua. Dissertação de Mestrado não-publicada, Curso de Pós-Graduação em Psicologia do Desenvolvimento, Universidade Federal do Rio Grande do Sul. Porto Alegre, RS.

Alves, P. B. (2002). Infância, tempo, atividades cotidianas de crianças em situação de rua: As contribuições da teoria dos sistemas ecológicos. Tese de Doutorado não-publicada, Curso de Pós-Graduação em Psicologia do Desenvolvimento, Universidade Federal do Rio Grande do Sul. Porto Alegre, RS.

Alves, P. B., Koller, S. H., Silva, A. S, Reppold, C. T., Santos, C. L., Bichinho, G. S., Prade, L. T., Silva, M. R. \& Tudge, J. (1999). A construção de uma metodologia observacional para o estudo de crianças em situação de rua: Criando um manual de codificação de atividades cotidianas. Estudos de Psicologia, 2, 289-310.

Aneci Rosa, C. S., Borba, R. E. S. R. \& Ebrahim, G. J. (1992). The street children of Recife: A study of their background. Journal of Tropical Pediatrics, 38, 34-40.

Aptekar, L. (1988a). Colombian street children: Their natural health and how they can be served. International Journal of Mental Health, 17, 81-104.

Aptekar, L. (1988b). Street children of Cali. Durham, NC: Duke University Press. 
Aptekar, L. (1989a). Characteristics of street children of Colombia. Child Abuse and Neglect, 133, 427-437.

Aptekar, L. (1989b). Colombian street children Gamines or Chupagruesos. Adolescence, 24, 783-794.

Aptekar, L. (1996). Crianças de rua nos países em desenvolvimento: Uma revisão de suas condições. Psicologia: Reflexão e Crítica, 9, 153-184.

Bandeira, D., Koller, S., Hutz, C. \& Foster, L. (1994). O cotidiano dos meninos de rua de Porto Alegre. Anais do XVII International School Psychology Congress, Tomo II (pp. 133-134). Campinas, São Paulo.

Bardin, L. (1979). Análise de conteúdo. (L. A. Reto \& A. Pinheiro, Trads.). São Paulo: Edições 70/ Martins Fontes. (Original publicado em 1977)

Brasil. (1990). Estatuto da Criança e do Adolescente (1990). Lei n. 8.069, de 13/07/1990. São Paulo: Cortez.

Brito, R. C. (1999). Uso de drogas entre meninos e meninas em situação de rua: Subsídiospara uma intervenção comunitária. Dissertação de Mestrado não-publicada, Curso de Pós-graduação em Psicologia do Desenvolvimento, Universidade Federal do Rio Grande do Sul. Porto Alegre, RS.

Caminha, R. M. (1999). A violência e seus danos à criança e ao adolescente. Em AMENCAR. Violência doméstica. Brasília: UNICEF.

Campos, H. R. \& Alverga, A. R. de (2001). Trabalho infantil e ideologia: Contribuição ao estudo da crença indiscriminada na dignidade do trabalho. Estudos de Psicologia (Natal), 6, 227-233.

Carpena, M. E. F. \& Koller, S. H. (1999). Famílias de meninos em situação de rua na cidade de Caxias do Sul: Locus de controle, situação atual de vida e expectativas para o futuro. Coletânea Cultura e Saber Psicologia, 3, 53-81.

Cecconello, A. M., De Antoni, C. \& Koller, S. H. (2003). Práticas educativas, estilos parentais e o abuso físico intrafamiliar. Psicologia em Estudo, 8, 45-54.

Cerqueira-Santos, E. C. (2004). Um estudo sobre a brincadeira entre criancas em situação de rua. Dissertação de Mestrado não-publicada, Curso de Pós-Graduação em Psicologia do Desenvolvimento, Universidade Federal do Rio Grande do Sul. Porto Alegre, RS. Disponível em www.ailha.com.br/ceprua

Forster, L. M. K., Barros, H. M. T., Tannhauser, S. L. \& Tannhauser, M. (1992). Meninos na rua: Relação entre abuso de drogas e atividades ilícitas. Revista da ABP-APAL, 14, 115-120.

Hecht, T. (1998). At home in the street: Street children of northeast Brazil. Cambridge: Cambridge University Press.

Koller, S. H. (1994). Julgamento moral pró-social de meninos e meninas de rua. Tese de Doutorado não-publicada. Curso de Pós-Graduação em Educação, Pontifícia Universidade Católica do Rio Grande do Sul. Porto Alegre, RS.

Koller, S. H. (2001). A escola, a rua e a criança em desenvolvimento. Em Z. A. P. Del Prette (Org.), Psicologia escolar e educacional: Saúde e qualidade de vida (pp. 159-176). São Paulo: Alínea.

Koller, S. H. \& Hutz, C. S. (1996). Meninos e meninas em situação de rua: Dinâmica, diversidade e definição. Coletaneas da ANPEPP: Aplicações da Psicologia na Melhoria da Qualidade de Vida, 1,11-34.

Maciel, C., Brito, S. \& Camino, L. (1997). Caracterização dos meninos em situação de rua de João Pessoa. Psicologia: Reflexão e Crítica, 10, 315-334.
Martins, R. A. (1996a). Censo de crianças e adolescentes em situação de rua em São José do Rio Preto. Psicologia: Reflexão e Crítica, 9, 101-122.

Martins, R. A. (1996b). Crianças e adolescentes em situação de rua: Definições, evolução e políticas de atendimento. Coletaneas da ANPEPP: Aplicaçoes da Psicologia na Melhoria da Qualidade de Vida, 1, 35-44.

Menezes, D. M. \& Brasil, K. C. T. (1998). Dimensões psíquicas e sociais da criança e do adolescente em situação de rua. Psicologia: Reflexão e Crítica, 11, 327-344.

Neiva-Silva, L. \& Koller, S. H. (2002). A rua como contexto de desenvolvimento. Em E. R. Lordelo, A. M. A. Carvalho \& S. H. Koller (Orgs.), Infäncia brasileira e contextos de desenvolvimento (pp. 205-230). São Paulo: Casa do Psicólogo; Salvador: Editora da Universidade Federal da Bahia.

Poleto, M., Koller, S. H. \& Wagner, T. C. (2004). Resiliência e desenvolvimento infantil de crianças que cuidam de crianças: Uma visão em perspectiva. Psicologia: Teoria e Pesquisa, 20, 241-250.

Raffaelli, M., Koller, S. H., Kuschick, M. Reppold, C., Krum, F. Bandeira, D. \& Simões, C. (2000). Gender differences in Brazilian street youth's family circumstances and experiences on the street. Child Abuse Neglect, 24,1431-1441.

Raffaelli, M., Koller, S. H., Reppold, C., Krum, F. \& Bandeira, D. (2001). How do street youth experience the street? Analysis of a sentence completion task. Childhood, 8, 396-415.

Rizzini, I. (1995). Deserdados da sociedade: Os "meninos de rua" da América Latina. Rio de Janeiro: Editora Universitária Santa Úrsula.

Rosemberg, F. (1996). Estimativa sobe crianças e adolescentes em situação de rua: Procedimentos de uma pesquisa. Psicologia: Reflexão e Crítica, 9, 21-58.

Santana, J. P. (2003). Instituições de atendimento a criancas e adolescentes em situacão de rua: Objetivos atribuidos por seus dirigentes epelos jovens atendidos. Dissertação de Mestrado não-publicada, Curso de Pós-Graduação em Psicologia do Desenvolvimento, Universidade Federal do Rio Grande do Sul. Porto Alegre, RS.

Santana, J. P., Alves, P. B., Araújo, S. A., Sinclair, A., Prade, L. T., Bichinho, G. P. B. \& Koller, S. H. (2000, Julho). Crianças em situação de rua: O que elas pensam sobre infância? Pôster apresentado no III Congresso Brasileiro de Psicologia do Desenvolvimento. Niterói, Rio de Janeiro.

Vasconcelos, M. M. P. (1996). Familia, trabalho e drogas: Estudo exploratório da representacão dos meninos de rua na cidade de João Pessoa sobre as suas condições de vida. Dissertação de Mestrado não-publicada, Curso de Pós-graduação em Psicologia, Universidade Federal da Paraíba. João Pessoa, PB.

Yunes, M. A. M., Arrieche, M. R. O. \& Tavares, M. F. A. (1997). Meninos(as) em situação de rua na cidade de Rio Grande: Vida na rua e vida na instituição. Momento, 10, 131-142.

Recebido: 19/04/2004

Última revisão: 03/11/2004

Aceite final: $22 / 11 / 2004$

Sobre as autoras

Juliana Prates Santana é Psicóloga formada pela Universidade Federal da Bahia, Mestre em Psicologia do Desenvolvimento pela Universidade Federal do Rio Grande do Sul e Doutoranda em Sociologia da Infância na Universidade do Minho, Braga, Portugal. É Membro do Centro de Estudos Psicológicos sobre Meninos e Meninas de Rua.

Thaís Mesquita Doninelli é Graduanda em Psicologia pela Universidade Federal do Rio Grande do Sul, Porto Alegre. Membro do Centro de Estudos Psicológicos sobre Meninos e Meninas de Rua.

Raquel Valiente Frosi é Graduanda em Psicologia pela Universidade Federal do Rio Grande do Sul, bolsista do PET/SESu, Membro do Centro de Estudos Psicológicos sobre Meninos e Meninas de Rua.

Sílvia Helena Koller é Psicóloga, Doutora em Educação (Pontifícia Universidade Católica do Rio Grande do Sul), Pesquisadora do CNPq e Professora do Curso de Pós-Graduação em Psicologia da Universidade Federal do Rio Grande do Sul, Porto Alegre. Coordenadora do Centro de Estudos Psicológicos sobre Meninos e Meninas de Rua. 